\title{
The Spatial Development Framework for Implementation of National Urban Policy
}

\author{
L. Boerboom ${ }^{1}$, M. Gibert ${ }^{2}$, M. Spaliviero ${ }^{3}$,G. Spaliviero ${ }^{4}$ \\ ${ }^{1}$ Faculty of Geo-Information Science and Earth Observation (ITC), University of Twente, Enschede, The Netherlands \\ ${ }^{2}$ Consultant urban and regional development, Barcelona, Spain \\ ${ }^{3}$ Regional Office for Africa (ROAf), United Nations Human Settlements Programme (UN-Habitat), Nairobi, Kenya \\ ${ }^{4}$ Consultant urban and regional development, Venice, Italy \\ l.g.j.boerboom@utwente.nl,mgibert@coac.net, mathias.spaliviero@unhabitat.org, giovanni@spaliber.com
}

\begin{abstract}
National Urbanization Policies (NUPs) are of particular importance in countries with rapid urbanization. Both for diagnosis for development of NUPs and for planning of implementation of NUPs we present a new methodology called the Spatial Development Framework (SDF). The SDF analyzes and describes with stakeholders the regional structure and interdependencies between settlements and evaluates the strengths and weaknesses of settlements. This is the basis for action planning by national, regional and local stakeholders.
\end{abstract}

We describe the methodology and show the preliminary results of the ongoing implementation of the methodology for the NUP implementation in Rwanda. We discuss the empirical value of the methodology, its integrative nature, the applicability to any spatial policy development and implementation, its data requirements, and its time input requirements.

We conclude that the Spatial Development Framework methodology complements NUPs be providing an empirical, integrated and by stakeholders shared understanding of the spatial structure of the country's settlements and development corridors. It serves realistic urban and regional development planning based on this shared understanding.

Keywords - matrix of functions, national urban policy, spatial multi-criteria evaluation, urban and regional planning. 


\section{I.INTRODUCTION}

A clear relation exists between the Gross Domestic Product of developing countries and the percentage of urban population. In higher middle income countries (US\$4000 - 12000 per capita annual GDP income) typically 50 to $90 \%$ of population live in cities. In lower middle income countries (US\$ $1000-4000$ per capita annual GDP income) between 20 and 70 percent of citizens live in cities. And finally, in low income countries (less than US\$ 1000 per capita annual GDP income) 10 to 50\% of people live in cities. (Urban Planning and Design Branch, 2014) Although a causality behind this relation has not been proven, and distribution of wealth is not measured., developing countries see urbanization as process to advance their wealth. With National Urban Policies (NUPs) they aim to stimulate and guide the urbanization process. Such National Urban Policy (NUP) is "a coherent set of decisions derived through a deliberate government-led process of coordinating and rallying various actors for a common vision and goal that will promote more transformative, productive, inclusive and resilient urban development for the long term (which can be from to 20 to 30 or even 100 years horizon).” (Urban Planning and Design Branch, 2014). It is developed by ministerial departments and local authorities with the involvement of urban stakeholders such as the private sector, civil society organization, and research and academic organizations. It results in a coordinating framework to address urban challenges to maximize benefits minimize adverse externalities. And it should be approved by the Government and ready for implementation. (Urban Planning and Design Branch, 2014)

NUPs need to vary between countries, since urbanization processes vary too, given different speeds of urbanization, resources available to invest in infrastructure and services, institutional capacities, etc. Yet a number of principles can be followed based on a study of NUPs in 20 countries around the world, with focus on low- and middle-income countries in the South (Turok, 2014). These principles are as follows. Governments require a coordinated approach to planning and managing cities and towns. Implementation requires a sustained technical process to develop the legal foundations, capable institutions and financial instruments to design and build more productive, livable and resilient cities and towns. An NUP requires 
active collaboration between spheres of government and devolution of appropriate responsibilities and resources. Also, compact and inclusive urban growth is to be promoted and city expansion to be reduced. Pro-active efforts are required to increase the quantity and quality of land and property developed within the urban core and along transport corridors. Land and infrastructure preparation in advance is less socially disruptive and more cost effective. And finally, urban policy requires a broader territorial perspective on metropolitan regions, including stronger connectivity between cities, towns and rural areas. Particularly for this last NUP principle, a methodological gap exists to turn national policy desires and targets into action. At national level, a NUP addresses the urban settlements of the nation. At local level, urban development plans are to get guidance and resources from the NUP, and thus realize local desires and policy objectives. But a methodology is missing to obtain this broader territorial perspective, understand the factual and perceived regional structure of urban functions and turn these into a coherent set of actions and consequent allocation of resources within and between settlements.

We present the Spatial Development Framework (SDF), a methodology that aims to compliment National Urban Policies and bridge the gap with urban development plans. The term Spatial Development Framework, its rationale and first conceptual design were conceived at UN Habitat by Mathias Spaliviero. UN Habitat brought together the authors of this paper to develop the methodology and implement it for the first time for the region of Darfur with the Government of Sudan with the help of the UN Habitat Sudan office and local consultants. A second instance has been applied to the Blue Nile state in Sudan.

It has further developed and in this paper we illustrate the SDF methodology applied to complement implementation of the National Urbanization Policy of Rwanda that is being drafted, because this paper is written for the Geotech 2015 conference in Rwanda, and hence interesting for the audience. Since it is an on-going process, we can only partially present results, which are therefore also preliminary. Yet we aim to increase awareness of the approach, and therefore will still describe the current state of affairs in the Rwandan case and resort to the earlier application in Darfur to illustrate remaining steps of the methodology in Rwanda. 


\section{II.SPATIAL DEVELOPMENT FRAMEWORK METHODOLOGY}

The Spatial Development Framework (SDF) is a methodology that has been designed to support national, regional and local government decision-making by setting out a 'spatial' vision and strategy specific to a particular region with a view to maximising the benefits from investments and bringing about more balanced territorial development patterns, ultimately contributing to peace and economic growth. Originally it was developed in the years 2012-2014 by the authors for the UN-Habitat, the United Nations Human Settlements Programme, office in Sudan. It was developed to support the territorial reconstruction and the donor-pledged investments for the war-torn region of Darfur in Sudan. It aimed to complement a key policy document, the Darfur Joint Assessment Mission (DJAM) report, which established a framework for reconstruction. The SDF methodology provided spatial understanding of the current spatial structure of the region of Darfur, a spatial structure that had been altered and become unknown with years of conflict. It provided the stakeholder views on this spatial structure. It evaluated the strengths and weaknesses of settlements in context of neighbouring settlements and infrastructures and thus developed a decision atlas. And finally it helped stakeholders to prioritize actions and allocate resources, considering the now understood new spatial structure of the region. Hence it operationalized the development policy. A former minister of infrastructure of Rwanda saw how the SDF could similarly be used to give hands and feet to NUPs, and hence an SDF project was initiated to complement the NUP of Rwanda, which is currently under development. First we explain the methodology in general, then more specifically.

The Spatial Development Framework methodology consists of three main methods (Fig. 1), adequately combined to overcome the limitations of each when taken individually, to the ultimate purpose of obtaining an accurate, unbiased and clearly defined Spatial Development Framework:

1. The Matrix of Function (MoF) is used to strategically categorise the network of urban settlements based on the mere availability, or non-availability, of functions ${ }^{1}$. It was developed from the

\footnotetext{
${ }^{1}$ NB: A "function" we define as every service, equipment, activity and facility which has an economic, administrative, social or cultural function in a given human settlement
} 
Scalogram method (Rondinelli, 1985) and renamed to MoF by Giovanni Spaliviero in regional development projects in West and North Africa in the 1980s (Spaliviero, 2015, Unité de Réalisation des Projets Pilotes, 1992, Unité Technique de Planification, 1986).

2. The Consultative trainings/workshops are used to prioritise areas for urban and socio-economic development, based on participatory discussions with relevant stakeholders.

3. The Spatial Multi-Criteria Evaluation (SMCE) is used to determine the short, medium and long term infrastructure and socio-economic investments, by assessing/evaluating the performance of key themes of urbanisation within the network of urban settlements.

The first two approaches lead to a preliminary spatial structure of development areas, development corridors, and nodal towns can be identified. Together with the third method these can be evaluated for the development needs and potentials. And based on these, stakeholders can perform action planning, which is to be politically validated and subsequently included in the budgeting procedures and other policy processes. (Fig. 1).

Although the SDF methodology complements the NUP, many other policies are to be reviewed to understand and act in the territory. Also, data and results of the SDF are to be communicated to and from the stakeholders context. And finally the results need to influence the annual and strategic budget allocation of the different spheres of government.

An SDF analysis is carried out by a team of regional and urban planners and experts in in spatial data processing and spatial decision support systems. This team needs to be supported by a technical committee with members from different ministries and agencies covering portfolios of spatial planning, infrastructure, housing, finance and economy, environment, agriculture, and others. And it needs to be supported by data providing organizations such as bureaus of statistics.

Figure 1: The Spatial Development Framework in policy, data, end user, and government funding context. 


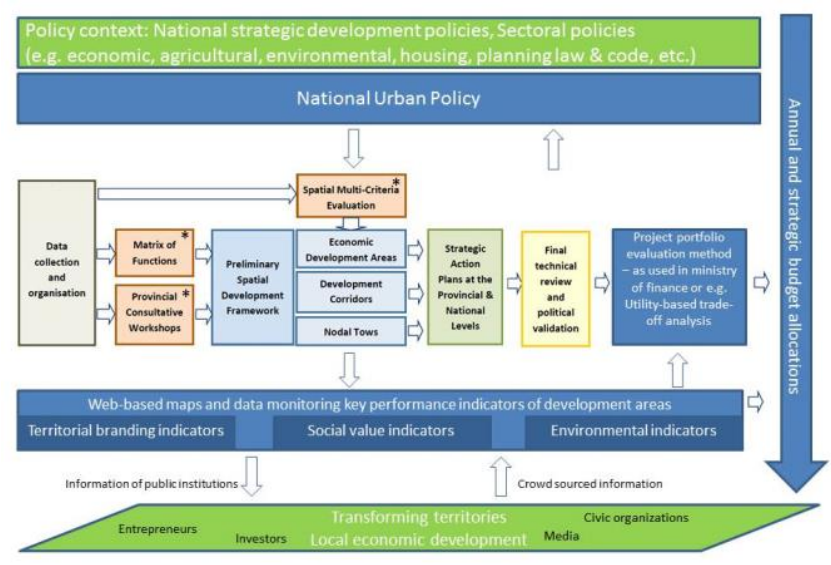

Next we describe the methodological steps in more detail, where we do realize that the individual methods.

In phase A the preliminary spatial structure is determined. It starts with the definition of the main spatial challenges and opportunities of the region (A1). It occurs through desk review of the existing strategic development plans as well as other relevant policy documentation and data related with spatial development in general at the different levels (national, regional, local, etc.). This study provides the basis to define the main spatial challenges and opportunities of the region.

Then the Matrix of Functions (MoF, Fig. 2) is used to determine the level of physical and socioeconomic development of the human settlements and its territorial linkages in the context of a given territory (A2), e.g. Rwanda. The MoF is a table where columns represent functions and rows represent the lowest possible level of administrative units e.g. sectors in Rwanda. The team establishes a list as comprehensive and exhaustive as possible of basic, intermediate and central functions, such as primary school, police station, car mechanic, pharmacy, or lawyer across 10 to 15 functional categories, such as, education, public utilities and facilities, law and security, health, financial services, or private professionals. Each category can consist of "functions", i.e. services, equipment, skills, activities, or facilities. Hence in the category education a primary school can be a function of basic settlements, a community college a function of intermediate towns, and a university a function of central towns. 
The purpose is to empirically derive the hierarchy of settlements rather than impose a desirable hierarchy and to analyse the distribution of existing and missing functions in the settlements.

To do so, it is essential to have an exhaustive list of all possible functions that make a difference between the administrative units for the specific country or region, i.e the prevalent distribution of functions.

Figure 2: An example of a fictional ordered Matrix of Functions with four levels (colors) of centrality.

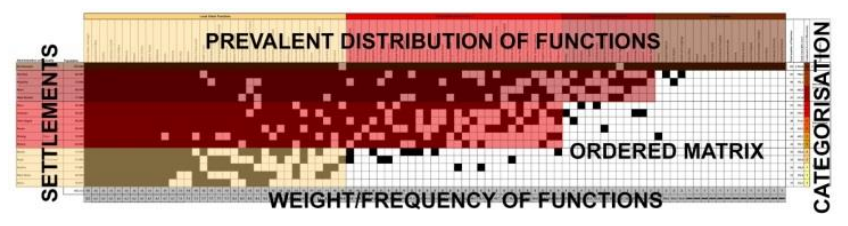

The data is collected through the distribution of a questionnaire. In it, government representatives make an inventory of the presence or absence of functions in the administrative units. The data is filled in the unordered MoF. The SDF team sums the number of times a function occurs, which is the function frequency, and by convention divides by 100 to obtain the function weight. Hence basic functions which occur often, obtain a low weight and rare central functions obtain a high weight. Therefore each black square in figure 2 represents a present function and has an associated weight. When the weights of all functions present in each administrative unit are summed, the "centrality score" emerges for each settlement. Then, after sorting by function weight and centrality score the "ordered matrix" is established. And finally the ordered matrix is interpreted to preliminarily distinguish basic from intermediate and from central towns. All calculations can be done in any software spreadsheet.

The MoF is complemented with an isopleth map (Fig. 3) showing the levels of centrality for each settlement in the administrative unit. The map can be drawn by hand or mapped in a geographic information system. From the isopleth map the spatial structure emerges. It visualises the "territorial linkages" of each settlement and identifies "clusters" of settlements (or areas of concentration of urban 
settlements) which are strongly interconnected and work cooperatively in terms of socio-economic activities. Under the strategy of socio-economic complementarity, the analysis of the existing and missing functions in the settlements within these "clusters", helps to define priority investments for clustering services and facilities, taking into account the proposed regional settlement system, the distribution of functions among settlements and the settlement hierarchy.

Figure 3: An example fictional isopleth map. Each isopleth represents a level in the centrality index. The higher the number isopleths around a settlement, the more central it is. The axes represent the road network.

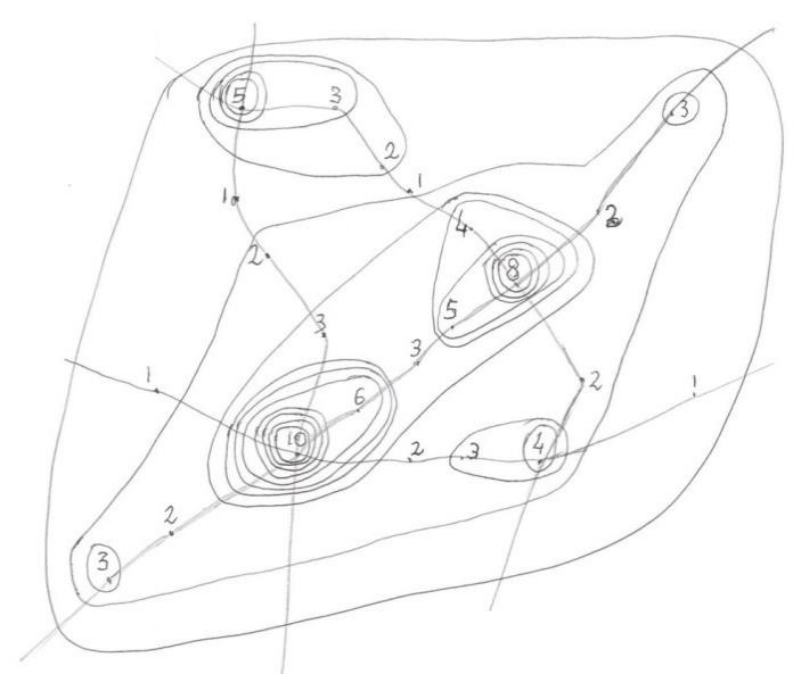

In the next step the SDF team organizes Consultative/Technical Workshops (A3) with national, regional and local authorities, technical partners and the private sector. During these sessions, preliminary results are discussed for their technical validation, while participants familiarise themselves with the methodology adopted and the spatial planning tools used (MoF and SMCE - Fig. 1). Through a participatory decision-making process settlements are ranked, aided by the preliminary ranking of the MoF, according to their urban, socio-economic development specific potential. The result is a ranking map of all the settlements and a list of recommendations on current and potential activities to be developed 
for each settlement.

Next the Preliminary Spatial Structure (A4) is derived, which is the result of the MoF and the Consultative Technical Workshops. It consists of a delineation of Economic Development Areas (EDAs), i.e. clusters of settlements considered high priority areas, representing the basic tenets, from which other two main structural elements (Development Corridors and Nodal Towns) are derived.

Economic Development Areas (EDA) are priority areas recognised as suitable for investment in economic, social and basic services, composed of a network of cities which support and complement each other in terms of socio-economic functions and road connectivity. Development Corridors (DC) are main (existing and proposed) routes of multimodal transport networks which enable connectivity among urban centres, nodal towns and/or EDAs, adjoining countries, regions and States. And Nodal Towns (NT) are existing urban settlements which are designated as future centres of economic activity, located strategically at border crossings (international/national gateways) or as nodes between EDAs to improve the socio-economic performance of a Development Corridor.

And the last step of the first phase (A5) is the spatial multi-criteria evaluation SMCE applied to the spatial structure of EDA's and nodal towns. A decision atlas is prepared on different themes. These themes correspond to the main guiding policy document. In Darfur this was the DJAM, in Rwanda the National Urban Policy.

In the SMCE method, as implemented in the ILWIS free and open source geographic information system software (Zucca et al., 2008, Sharifi and Retsios, 2003, Ferretti and Pomarico, 2012), a criteria tree is formed consisting of the overall objective of the evaluation, its sub-objectives, and criteria that are applied to indicator maps. Criteria evaluate the performance of territorial units with respect to the objectives formulated. Indicator maps are made into raster maps which are aggregated by means of a weighted summation. Since all raster maps are first standardized so that the pixels in those maps have a value between zero, meaning unsuitable for the objective they aim to measure, and one, meaning suitable for that objective, the overall "composite index map" is a map with pixels from zero to one. 
In the SDF the objectives and criteria are taken from the policy documents. indicators from datasets in government agencies and standardization rules or so called "value functions", i.e. criteria, from the standards and norms that have been formulated in national laws, guidelines, policies, etc. Criteria tree and priorities of different objectives are assessed by the technical committee at first and politically validated through the consultative workshops in the administrative units in the country or region, and through political agreement in national or regional government. Hence the SDF team's task is to propose a criteria tree structure and be explicit about the sources, of objectives, criteria and indicators and adapt according to technical and political inputs.

Then in the second phase, phase B, the action planning takes place (B1). It outlines strategic action plans, including recommendations that take into account the outcomes of the MoF, the SMCE, the Statespecific consultative workshops and on-going/ planned main infrastructural and economic interventions. These strategic action plans involve the type of capital expenditure needed to improve conditions in the proposed Economic Development Areas, Development Corridors and nodal towns. Action plans result from discussions in workshops of representatives of stakeholders.

Next follows the political validation (B2) of the action plans occurs in a final consultative workshop, bringing together high-level representatives from the national, regional and local government as well as bi-lateral and multilateral partners such as donors, UN agencies, international NGOs, etc. Finally, the SDF team prepares a last revision, completing the document for publication and dissemination purposes (B3).

\section{III.RESULTS}

At the time of writing, the SDF methodology is being applied in Rwanda, and only preliminary results can be presented. Also we will not be able to describe in detail each step, because each is worth a paper in and of itself. Hence here we present the main results obtained so far and compliment with results from the previous application of the methodology in Darfur to provide a complete overview of methodology 
results.

The Government of Rwanda, with the aim to transform the country into a middle-income nation, targets the country to develop from the current $20 \%$ of population living in urban settlements, to $35 \%$ by the year 2020 (Republic of Rwanda, 2012). In alignment, the Economic Development and Poverty Reduction Strategy (EDPRS II), identified six secondary cities as priority regional centres of growth and investment, to promote a more balanced regional development and increase opportunities to off-farm employment. To achieve these strategic objectives, a National Urbanisation Policy (NUP) has been drafted to guide the adequate urbanisation process over the next 30 to 50 years.

Obviously the NUP document is a more complex document than we describe here. It has maked its policy and institutional embedding explicit, as well as its challenges, rational and perspectives. Core to the draft NUP are four pillars captured with keywords "Coordination", "Densification", "Conviciality", and "Economic growth". With coordination The NUP aims to ensure multi-level institutional coordination, good governance and effective urban planning and management, applying appropriate tools and ensuring coherence between different types of planning and coherent action. With densification the NUP aims to use land efficiently by phasing investment strategically and integrate green principles within development, applying principles and standards guiding the development of efficiently serviced urban neighbourhoods to high population numbers within urban areas and preserve valuable natural and agricultural resources. With conviviality the NUP aims to assure quality of life in all facets, with social inclusion and cultural preservation as integral parts. And with economic Growth the NUP is to achieve economic growth which is sustainable and guided by green economic criteria, whereby urban areas are centres for innovation and entrepreneurship and sources for socio-economic services and opportunities. (Ministry of Infrastructure, 2015).

The policy context for the SDF is bigger than the NUP. It consists, among others, the Second Economic Development and Poverty Reduction Strategy (EDPRS 2), the draft National Urbanisation Policy, the SMART Rwanda Master Plan 2015-2020, the Youth Sector Strategic Plan 2013-2018, the Rwanda 
Private Sector Development Strategy-Prepared for the EDPRSII: 2013-2018, the Strategic Plan for the Transformation of Agriculture in Rwanda, the Housing Policy, the Urban Planning law and Building Code, and the decentralization policy.

An SDF team was formed with 6 members covering the expertise of urbanism, regional planning, geographic information science, and spatial decision support systems. Three team members were Rwandan, GIS experts from the University of Rwanda's Centre for Geographic Information Systems and Remote Sensing (CGIS). Although, the team was based at the Ministry of Infrastructure and tied to one of the departments, none of the team members were staff members of the ministry. A technical committee was formed with members not only of the Ministry of Infrastructure but also of the Rwanda Housing authority, the Rwanda Natural Resources Authority, the Ministry of Finance and Economic Planning, the National Institute of Statistics of Rwanda, and the Global Green Growth Institute/Rwanda.

One of the first activities of the SDF team was to invite the district administrators and politicians per province and explain the SDF methodology, its context and process. The rationale of a Spatial Development Framework to complement and implement a national urbanization policy was established and the key role of districts in this process.

In the meantime the main spatial challenges (Fig. 4) and opportunities (Fig. 5) of the country's districts were reviewed in the SWAT analyses of the District Development Plans and in the workshops, (step A1) Also policy documents in different sectors surrounding the NUP, were used in this step to arrive at an insight of challenges and opportunities.

Figure 4: Overview of challenges of main urbanized districts of Rwanda. 


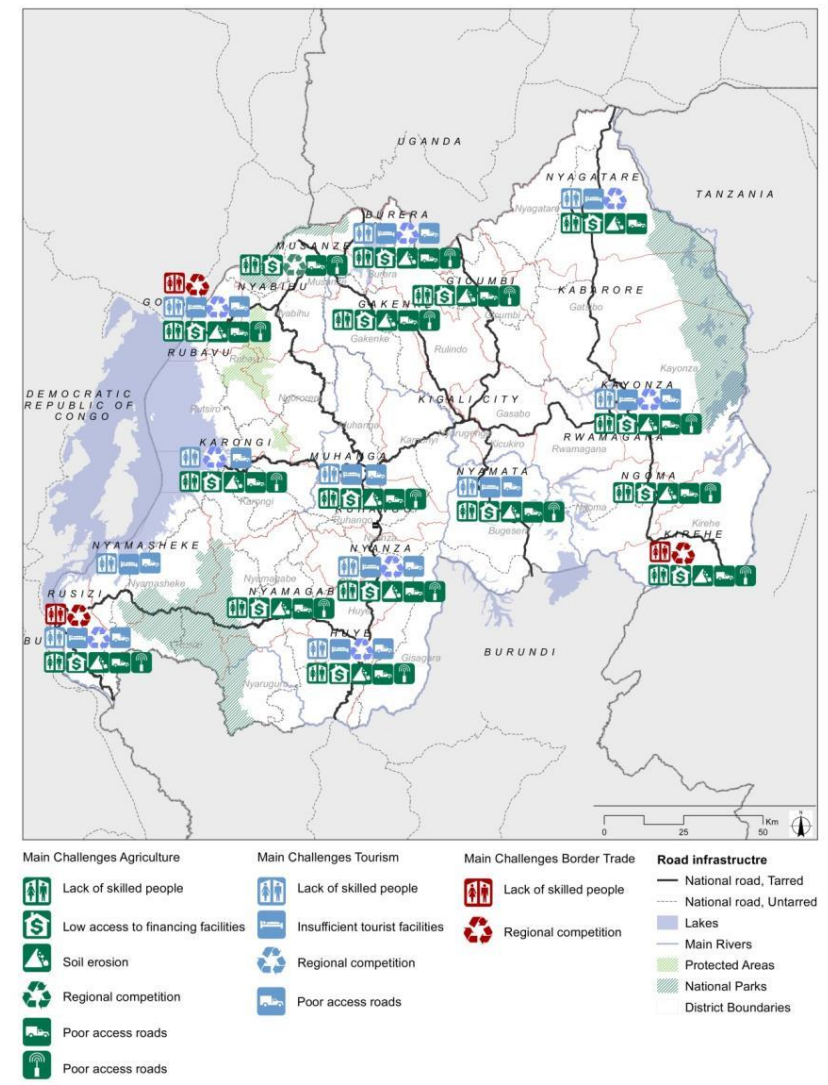

Figure 5: Overview of economic potentialities of settlements of Rwanda. 


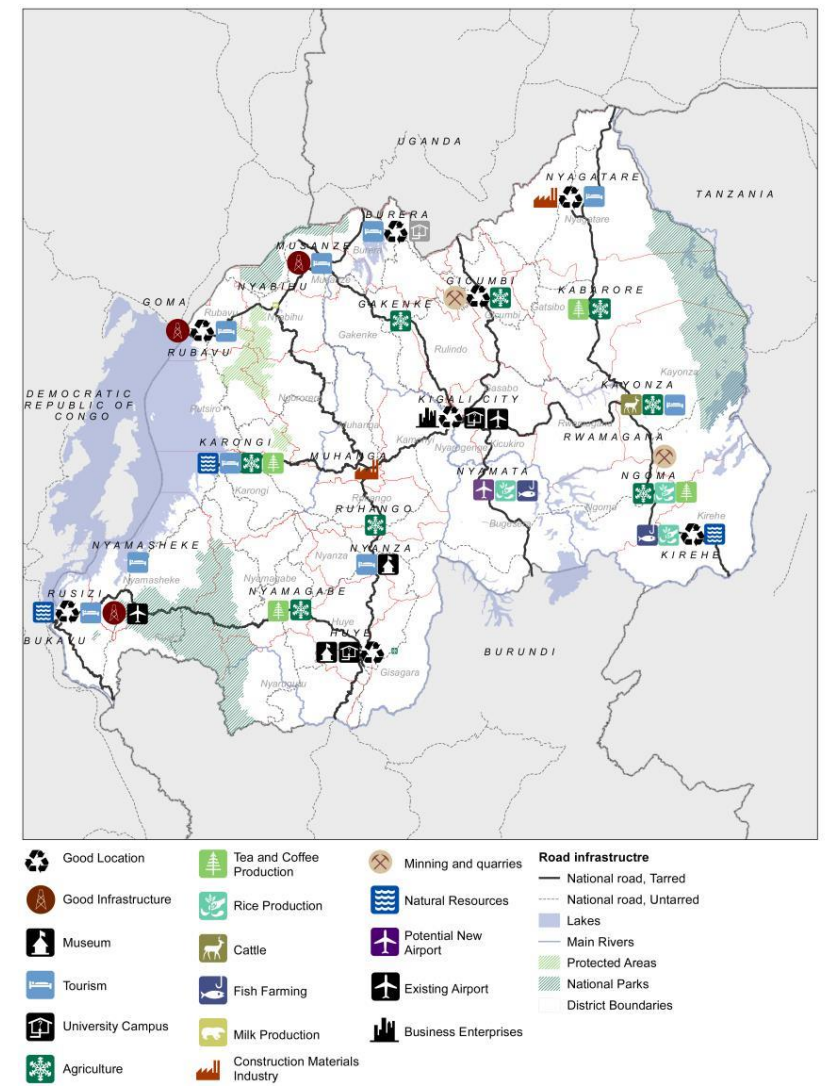

During the other preparatory studies, data was collected through a survey to all 30 district administrations where the ministry of infrastructure asked administrators to fill in the presence or absence of 79 functions in the 416 sectors of their districts. The SDF team collected the results in the unordered Matrix of Functions, which was then ordered (Fig. 6). The MoF shows that truly basic functions that occur in almost all sectors of Rwanda are primary school, lower secondary school, government-assisted health center (GAHFs), upper secondary school, church/mosque, national electricity on grid. An example of rare functions are the function "fire station" that can only be found in the capital Kigali and in the city of Rubavu on the border with Congo, or the function "university hospital" that can be found in the city of Huye.

The jumps in centrality scores and distribution of functions were used to differentiate the Main Urban Centre (MUC), Intermediate Urban Centres (IUC) 1 and 2, and Local Urban Centres (LUC) (Table 1). 
The centrality scores indicate that two of the by EDPRS2 policy proposed secondary towns are of a different category, IUC2, than the others which are in IUC 1. All other sectors were classified as LUC, Local Urban Also, except for these two settlements, all IUC2 settlements became a nodal town status in the Spatial Development Framework. And typically they are literally located at the crossroads in the national road network.

Figure 6: The Matrix of Functions for the whole of Rwanda, distinguishing the Main Urban Center, Intermediate Urban Centres 1, Intermediate Urban Centres 2, and Local Urban Centres.

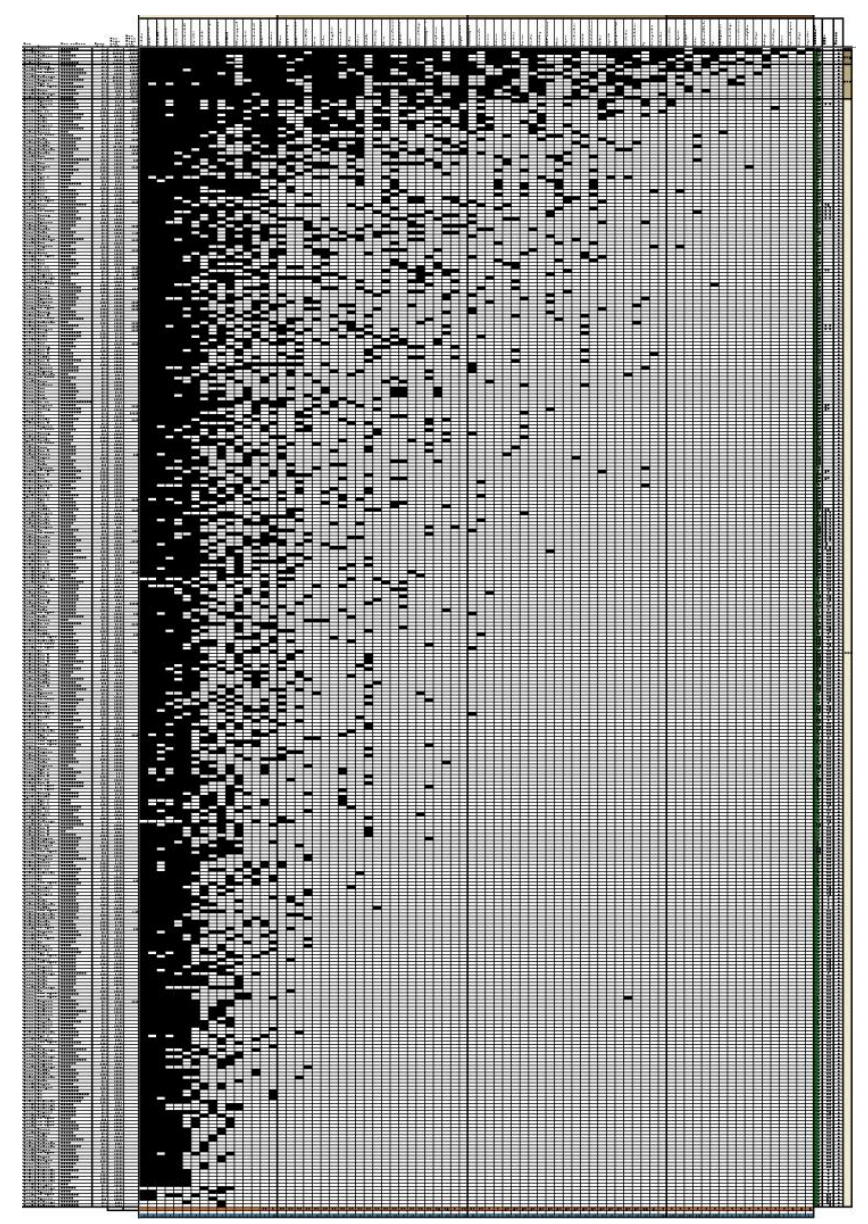

Table 1: Cities listed in the top of the MoF, their centrality score, level of hierarchy, and settlement classification. * are by NUP policy proposed secondary cities. 


\begin{tabular}{|c|c|c|c|}
\hline & Centrality & Level of & Settlement \\
\hline City & Score & hierarchy & classification \\
\hline Kigali & 695 & 12 & MUC \\
\hline Huye * & 489 & 8 & IUC1 \\
\hline Rubavu * & 264 & 6 & IUC1 \\
\hline Rusizi * & 239 & 6 & IUC1 \\
\hline Musanze * & 230 & 6 & IUC1 \\
\hline Karongi & 193 & 5 & IUC2 \\
\hline Nyamagabe & 171 & 5 & IUC2 \\
\hline Nyamasheke & 168 & 5 & IUC2 \\
\hline Muhanga * & 166 & 5 & IUC2 \\
\hline Nyagatare * & 165 & 5 & IUC2 \\
\hline Ngoma & 150 & 4 & IUC2 \\
\hline Rwamagana & 141 & 4 & IUC2 \\
\hline Nyanza & 140 & 4 & IUC2 \\
\hline Ruhango & 105 & 3 & IUC2 \\
\hline Gicumbi & 105 & 3 & IUC2 \\
\hline
\end{tabular}

Also the jumps in centrality score between the top two cities and the rest were rather large and several levels of hierarchy were inserted. These levels were used to create the isopleth map (Fig. 7) of the Matrix of functions. Hence a structure of cities emerges. 
Figure 7: Isopleth map of the Matrix of Functions of Rwanda.

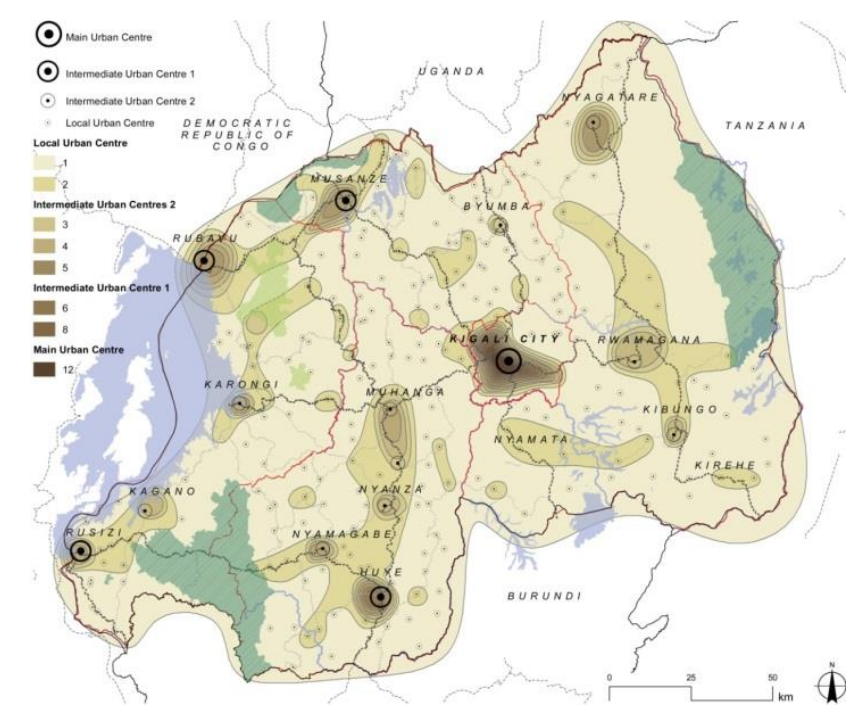

In the consultative workshops (A3) the SDF team visited all provinces and technical district representatives were presented with findings and discussed to improve a preliminary spatial structure (Fig. 8). In this meeting also the next step was conceptually presented (A5), the SMCE analysis.

Figure 8: Preliminary spatial structure map with Economic Development Areas, capital, secondary cities, nodal towns, and primary and secondary corridors. 


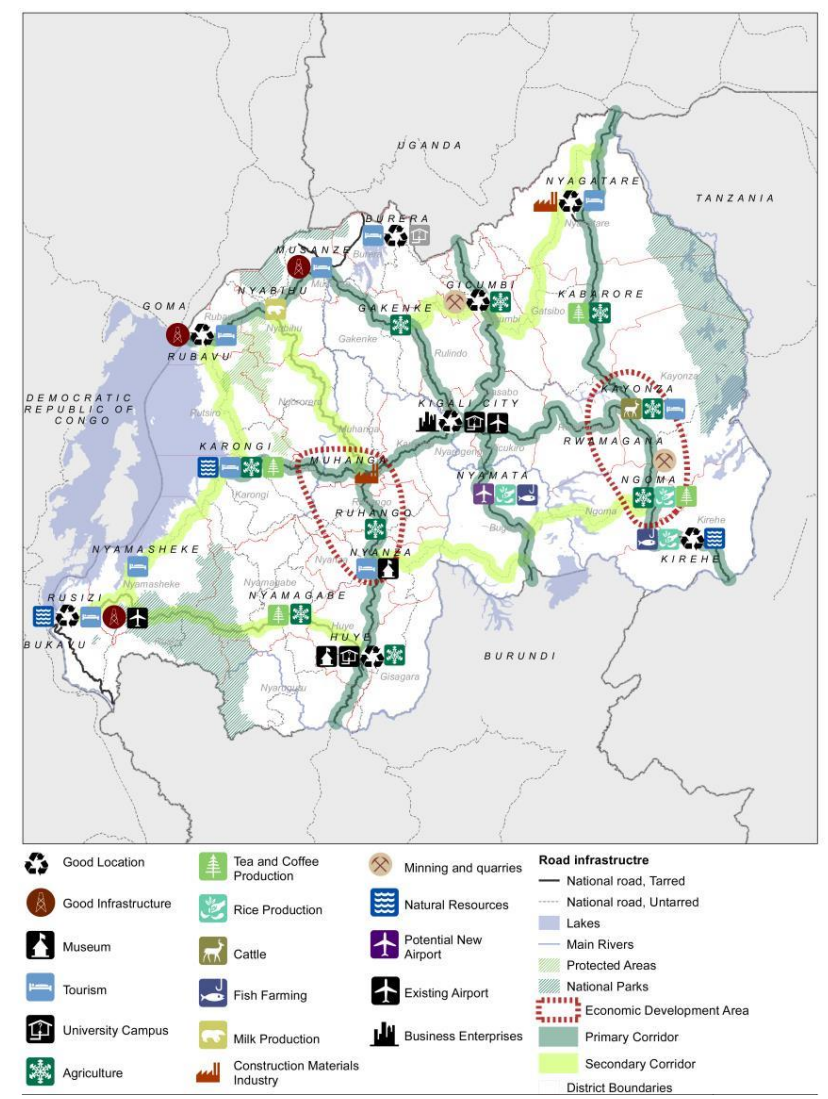

The SMCE has been structured around the four pillars of the NUP, "Coordination", "Densification", "Conviciality", and "Economic growth". For each of these themes a separate spatial evaluation will be made. Presenting each evaluation would be too much detail for this paper. Instead we present part of one example criteria tree (Fig. 9). Note details such as references to policy documents, and standards, tables systematically describing indicators as well as the criteria applied. Also note that weights are still missing. The SDF team will assume an equal importance of objectives and criteria in the first proposed decision atlas maps and discuss priority of objectives with the technical committee.

Figure 9: Example partial criteria tree for pillar economic growth. 


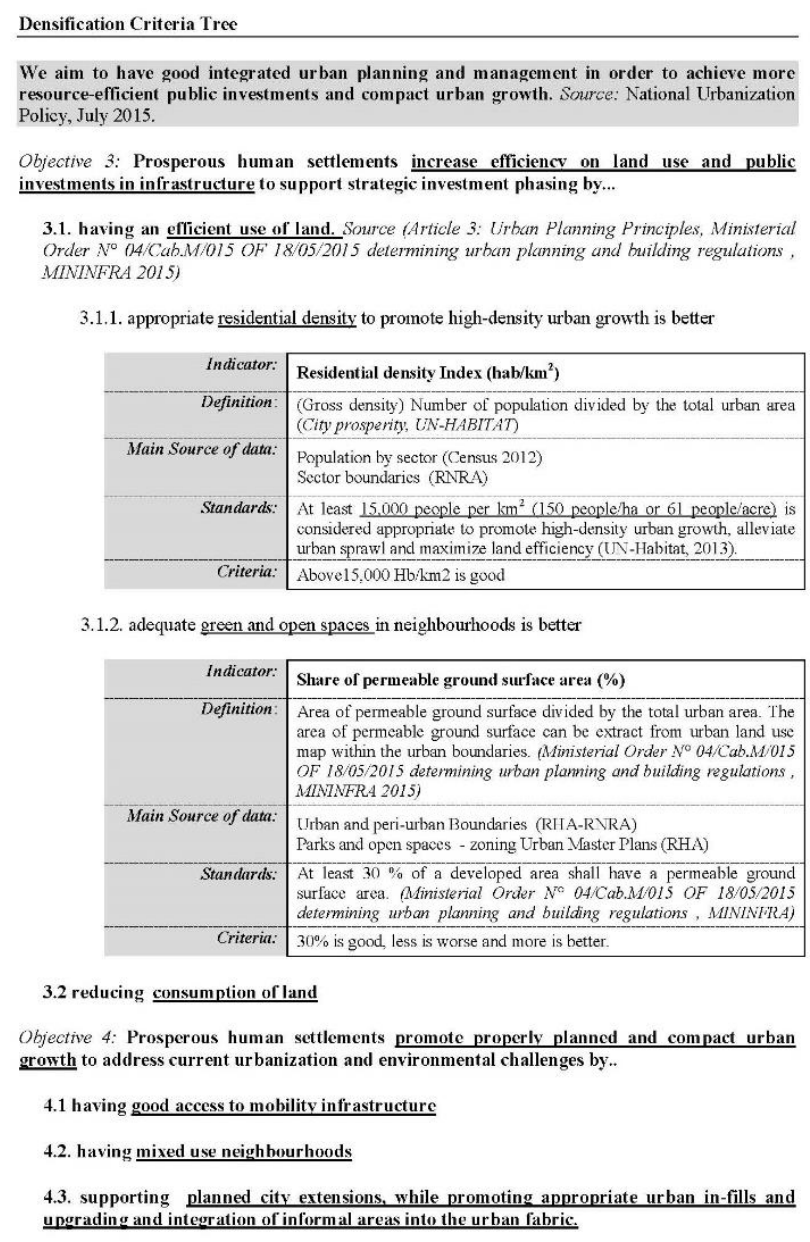

Given that we have not completed this part of the analysis we present an example "decision atlas" sheet that was prepared for the earlier SDF application in the region of Darfur in Sudan (Fig. 10). Four similar outputs will be produced for each of the four NUP pillars.

Figure 10: Example sheet from decision atlas of Darfur. The large map shows the overall healthcare situation evaluation. The small maps evaluate sub-objective in terms of suitability for development. Suitability is measured with utility values ranging from 0 (light blue) to 100 (dark blue). 


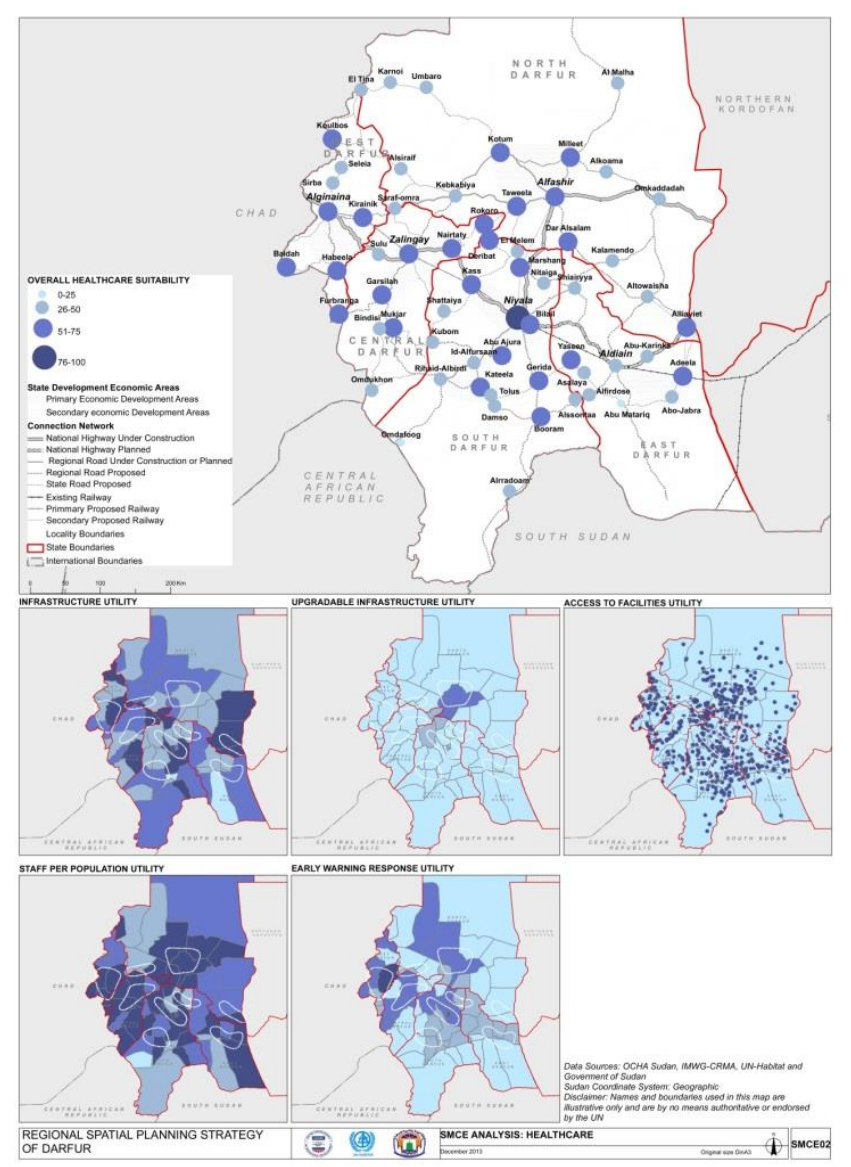

The role of the technical committee in phase $\mathrm{A}$ is to provide feedback on the process, provide data, policy documents, and standards and norms, and evaluate output. In phase B the SDF team again organizes consultative action planning workshops with the district officials in each of the Rwandan provinces. All results from phase A are presented, technically validated, and used in brainstorming sessions to review planned actions and consider new action in the districts' settlements in an integrated way with and between sectors as well as within and between settlements. This results in action plans, of which a Darfur example is presented due to the fact that the Rwandan SDF development process has not yet arrived at this face. (Fig. 11). Each of the elements in the spatial structure, i.e. the Economic Development Areas, the nodal towns and the primary and secondary corridors is briefly described in terms of key characteristics, challenges and opportunities, from phases A1 and A5. And then strategic action recommendation are to be formulated as specific as possible. And thus the action recommendations for 
each of the settlements are based on the findings of phase A and the place of the settlement in the surrounding spatial structure. Finally, the whole SDF analysis is reported and presented to cabinet and/or parliamentarian approval.

Figure 11: Example action plan of the state of North Darfur in the region of Darfur.

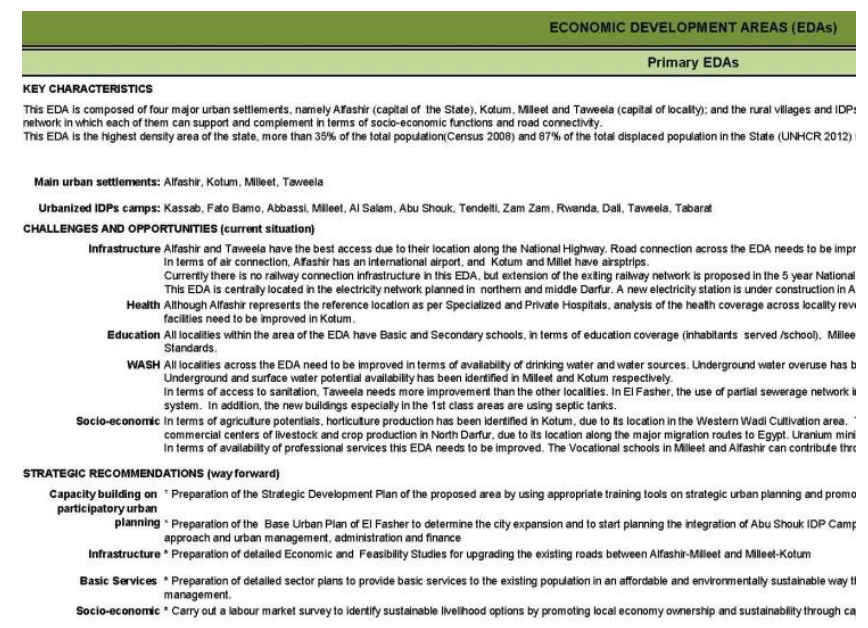

\section{IV.DISCUSSION}

As one of the benefits of the SDF methodology, we see the fact that the outcome of action plans Is based on empirical understanding of the regional structure, the territorial dynamics, and the place settlements take in this structure. It is not based on whatever stakeholders believe the reality to be or like the reality to be. Hence a real gap between current and desired situation can be formulated to guide realistic planning. From this, the action plans define spatially specific policy targets to enhance or change the structure where needed.

A benefit of the empirical approach is that the SDF methodology is not sensitive to the constant change of the definition of "urban areas" over the years and between the different census, institutions, development plans and laws. This continuous change of definition makes the evaluation of government target achievement difficult. And of course the definition of urban areas that is not basedon empirical evidence incurs the risk of not reflecting the urbanisation process on the ground 
The SDF is a very integrative method. It places the NUP in the context of other policies. It considers different sectors in the MoF and different policy objectives in the SMCE analysis. And it involves stakeholders from different territorial units to collaborate on regional and settlement development.

The scope of the applicability of the Spatial Development Framework methodology is wider than presented here. It has been used for other spatial development policies, such as the one in Darfur. In essence it can be used for all policy domains where the structure of territorial functions, derived through the MoF, leads policy implementation. In the Rwandan case it is applied to the country as a whole, but it can also be used for regions or provinces.

A golden rule is that new data is not to be collected for the SDF. Except for the data for the MoF, which appears to be quite easily collectable with little room for error, all data comes from government agencies, international agencies, or NGOs. Hence the technical committee plays a crucial role in the development of a Spatial Development Framework. And the SDF team needs to establish the quality of data. The report on SMCE analysis needs a description of the quality of data for each of the themes evaluated.

The SDF projects in Rwanda and Sudan (Darfur region and Blue Nile state) were organized through a team of local and international consultants. In both cases delays occurred and projects that were planned for 6-9 months eventually lasted 18 months. It required flexibility of time and funding by both funding parties and the SDF team. Such delays can be explained by the large number of parties to be worked with, and time consuming processes of obtaining data. Hence we propose to develop the SDF methodology as an institution for recurring evaluation and steering and embedding in annual processes of public administration.

\section{V.CONCLUSIONS}

Increasingly low and middle income countries develop National Urbanization Policies (NUP) to guide urbanization and increase wealth and well-being. The Spatial Development Framework methodology 
complements NUPs be providing an empirical, integrated and by stakeholders shared understanding of the spatial structure of the country's settlements and development corridors. Based on the shared understanding of the realities of the existing spatial structure, stakeholders in the territorial units can develop strategic action plans, which are coordinated between these units.

\section{REFERENCES}

Ferretti, V. \& Pomarico, S. 2012. An integrated approach for studying the land suitability for ecological corridors through spatial multicriteria evaluations. Environment, Development and Sustainability15, 859-885.

Ministry Of Infrastructure 2015. National Urbanization Policy (Draft 12.6.2015). In: INFRASTRUCTURE, M. O. (ed.). Kigali: Republic of Rwanda, Ministry of Infrastructure.

Republic Of Rwanda 2012. Rwanda Vision 2020. Revised 2012.

Rondinelli, D. A. 1985. Applied Methods of Regional Analysis: The Spatial Dimensions of Development Policy, Boulder and London, Westview Press.

Sharifi, M. A. \& Retsios, V. Site selection for waste disposal through spatial multiple criteria decision analysis. In: Proceedings of the 3rd International conference on decision support for telecommunications and information society DSTIS. 3rd International conference on decision support for telecommunications and information society DSTIS, 4-6 September 20032003 Warsaw, Poland. 
Spaliviero, G. 29-10-2015 2015. RE: Email Re: SDF paper Geotech Rwanda v2.docx (pers. com 29-102015).

Turok, I. 2014. The Evolution of National Urban Policies: A Global Overview, UN-Habitat (United Nations Human Settlements Programme).

Unité De Réalisation Des Projets Pilotes 1992. Projet pilote du village rural integre d'el karma (Kairouan). Tunis.

Unité Technique De Planification 1986. Etude socio-demographique et economique de la region de Kolda. Dakar.

Urban Planning And Design Branch 2014. National Urban Policy: Framework for A Rapid Diagnostic. UN-Habitat (United Nations Human Settlements Programme).

Zucca, A., Sharifi, A. M. \& Fabbri, A. G. 2008. Application of spatial multi-criteria analysis to site selection for a local park: A case study in the Bergamo Province, Italy. Journal of Environmental Management, 88, 752-769. 